\title{
LEVANTAMENTO DO PERFIL E AVALIAÇÃO DA FROTA DE VEICULOS DE PASSEIO BRASILEIRA VISANDO RACIONALIZAR AS EMISSÕES DE DIÓXIDO DE CARBONO
}

\section{Brazilian passenger vehicle fleet profile survey and evaluation to rationalize carbon dioxide emissions}

Leonardo Eustáquio Guimarães Doutorando pelo Programa de Pós-Graduação em Ciências Ambientais da UFG

Universidade Federal de Goiás Goiânia/GO - Brasil leonardo@padrao.eng.br

Francis Lee Doutora em Economia Aplicada pela Universidade Federal de Viçosa (UFV) Professora Adjunto I da Universidade Federal de Goiás Goiânia/GO - Brasil francisleerib@gmail.com

Artigo recebido para publicação em 15/03/2010 e aceito para publicação em 09/11/2010

RESUMO: O objetivo deste trabalho foi levantar e avaliar a frota de veículos de passeio brasileira, com vinte anos ou mais de uso, movidos à gasolina, bem como quantificar suas emissões de dióxido de carbono. A intenção foi avaliar o investimento necessário para retirar esses veículos de circulação, confrontando-o com as emissões evitadas e com o valor de mercado dessas emissões. Pelos resultados encontrados as emissões fósseis de $\mathrm{CO}_{2}$ evitadas, com a retirada de circulação destes veículos são de aproximadamente sete milhões e duzentos mil créditos de carbono.

Palavras-Chave: Aquecimento global. Efeito estufa. Dióxido de carbono. Emissões evitadas. Créditos de carbono.

ABSTRACT: The objective of this study was to collect and evaluate the fleet of passenger cars in Brazil, with twenty or more years of use, gasoline-powered, as well as quantifying their emissions of carbon dioxide. The intention was to evaluate the investment required to remove these vehicles from circulation, comparing it with the avoided emissions and the market value of these emissions. The results found the fossil $\mathrm{CO}_{2}$ emissions avoided, with the removal of such vehicles are approximately seven million two hundred thousand carbon credits.

Keywords: Global warming. Greenhouse effect. Carbon dioxide. Avoided emissions. Carbon credits. 


\section{EMISSOES DE CO, DEVIDO AO TRANSPORTE DE PASSAGEIROS EM VEÍCULOS LEVES}

Uma grande parcela da emissão de gases de efeito estufa se deve à descarga dos veículos automotores. Assim, governos de vários países, demonstrando preocupação com o aumento da temperatura média do planeta nas últimas décadas, têm adotado medidas para controlar e minimizar a emissão desses gases. A Alemanha é um exemplo de país que adotou recompensa de natureza financeira para estimular a população a se desfazer de seus veículos com mais de nove anos de uso trocando-os por outros com até um ano (EURONEWS, 2009).

Segundo o CNT (2007) o Brasil é responsável pela emissão de 1,70 bilhões de toneladas de dióxido de carbono por ano e o setor de transportes responde por $9 \%$ destas emissões. Deste quantitativo $88,31 \%$ devem-se aos transportes rodoviários e 32,5 milhões de toneladas são produzidas pelos veículos leves.

Os principais gases de efeito estufa originados do consumo do combustível fóssil do tipo gasolina são o Dióxido de Carbono $\left(\mathrm{CO}_{2}\right)$, o Metano $\left(\mathrm{CH}_{4}\right)$, os Clorofluorcarbonetos (CFC's) e o Óxido Nitroso $\left(\mathrm{N}_{2} \mathrm{O}\right)$ (SZWARCFITER, 2004). Entre esses gases o $\mathrm{CO}_{2}$ é considerado o principal responsável pelo efeito estufa (SZWARCFITER, 2004), sendo que sozinho ele responde por cerca de $64 \%$ do mesmo, quando considerados todos os gases de efeito estufa (MEIRA, 2002).

Ainda, segundo o relatório IPCC (2007), o dióxido de carbono responde por $97 \%$ das emissões de gases de efeito estufa, quando consideradas as emissões somente de fontes móveis. $\mathrm{O} \mathrm{CO}_{2}$ tem um efeito de alteração na temperatura superior ao metano por permanecer na atmosfera por um prazo muito superior (ALVIM, FERREIRA e VARGAS, 2008).

Segundo a Empresa de Pesquisa Energética (2009), o setor de transportes é o maior responsável pela geração de poluentes lançados na atmosfera.

Para Meyer (2001) a emissão de gases de efeito estufa para cada idade de veículo está relacionada com a quilometragem média anual percorrida, $o$ número de veículos em circulação e o fator de emissão. Por sua vez, o fator de emissão é função de diversas variáveis, entre elas o ano de fabricação, o estado de sucateamento e regulagem do veículo. A autora demonstra que a vida útil média da frota brasileira de veículos do tipo automóvel é de vinte anos. O Sindipeças (2008) considera a vida útil teórica de 20 anos para esses mesmos veículos.

Enfocando o ano de fabricação, uma das medidas mais eficazes adotadas para a contenção das emissões no Brasil foi estabelecida com a criação do Programa de Controle da Poluição do Ar por Veículos Automotores/PROCONVE, regulamentada pela Resolução $n^{\circ}$. 18/86 do Conselho Nacional do Meio Ambiente/CONAMA. Como resultado desse trabalho a Lei Federal n ${ }^{\circ} .8723$ de 29 de outubro de 1993 definiu os limites de emissão para veículos leves e pesados (CETESB, 2009).

Segundo Szwarcfiter (2004), com a implantação do controle da emissão de poluentes a nível internacional, os automóveis sofreram uma evolução tecnológica no que se refere ao potencial poluente. Com isso, houve uma redução das emissões veiculares mesmo com o aumento da frota. Porém, com relação aos veículos fabricados antes da definição destes limites, é preciso adotar medidas para melhorar sua curva de sucateamento e, por conseqüência, diminuir a emissão total por essa parcela da frota.

Mesmo com os sucessivos recordes de vendas de veículos zero-quilômetro, a frota brasileira tem se renovado lentamente devido ao elevado número de carros antigos em uso. Percebe-se ainda que as vendas de carros novos estão concentradas nos grandes centros urbanos. Dados da Federação Nacional da Distribuição de Veículos Automotores (Fenabrave) mostram que 20 municípios brasileiros receberam metade de todos os automóveis vendidos no ano de 2008. A outra metade foi distribuída entre os mais de cinco mil municípios do País. As cidades que lideram as compras são São Paulo, Belo Horizonte, Curitiba e Rio de Janeiro (SILVA, 2008).

O Proconve atua somente sobre veículos novos e, por conseqüência, não regulamenta os veículos existentes (mesmo considerando os veículos fabricados em conformidade com as normas do programa) que devido à manutenção inadequada, podem provocar um aumento significativo das emissões veiculares. É necessário, portanto, que se criem mecanismos para, em conjunto com o Proconve, limitar a emissão de 
poluentes por veículos leves usados (SZWARCFITER, 2004).

A tecnologia implantada para diminuição da emissão de poluentes (sistemas de controle das emissões) é composta principalmente pelos seguintes equipamentos: conversor catalítico, injeção eletrônica e sensor de oxigênio. No conversor catalítico as moléculas dos gases poluentes reagem entre si formando subprodutos mais inofensivos, como a água, anidrido carbônico e nitrogênio (SZWARCFITER, 2004). Já a injeção eletrônica e o sensor de oxigênio procuram assegurar uma queima completa do combustível, fator determinante para a limitação da emissão de poluentes.

De acordo com Szwarcfiter (2004), veículos com mau funcionamento do sistema de controle das emissões podem poluir, em alguns casos, mais do que veículos antigos, fabricados antes do estabelecimento do Proconve. Dessa forma, é necessária a implantação de programas de inspeção e manutenção veicular para automóveis existentes, como o modelo adotado em cidades como São Paulo, que já realizam a inspeção técnica veicular no ato da vistoria obrigatória do veículo.

\section{Questão Científica e Justificativa}

Neste trabalho levantou-se e avaliou-se a frota de veículos de passeio brasileira, com vinte anos ou mais de uso, movidos à gasolina, bem como se quantificou suas emissões de dióxido de carbono. Essas emissões foram quantificadas da data atual até o ano de 2050 , ou seja, até o sucateamento de $99,9 \%$ da frota avaliada.

O objetivo foi avaliar o investimento necessário para retirar esses veículos de circulação, confrontando-o com as emissões evitadas e com o valor de mercado dessas emissões.

De posse dessa avaliação será possível subsidiar os órgãos governamentais em decisões que poderão gerar ações que efetivamente irão contribuir para a retirada dessa frota de circulação evitando-se as emissões.

\section{PERFIL DA FROTA BRASILEIRA}

O perfil da frota circulante brasileira de veículos de fabricação nacional é apresentado na Tabela 1, extraída de Sindipeças (2009). Segundo Silva (2008), os dados do Sindipeças são mais confiáveis que os do Denatran, pois leva em conta o sucateamento não previsto devido a acidentes e roubos. Por esta tabela é possível depreender que os veículos de passeio em 2008 representam 80,01\% da frota total (se considerados os de passeio, comerciais, caminhões e ônibus). Nesta tabela é possível verificar ainda que esta frota passou de pouco mais de 56.000 veículos na década de sessenta para quase 22.250.000 de unidades em 2008.

Verifica-se, conforme os dados apresentados na Tabela 2, que os automóveis leves circulantes no Brasil têm idade média igual ao restante da frota, ou seja, nove anos.

Pela Tabela 3 é possível apurar o percentual de veículos movidos a gasolina referente ao período do início do PROALCOOL até o ano de 1990, objeto deste trabalho. Como não existem dados referentes a frota movida exclusivamente à gasolina, esses percentuais serão aplicados sobre a frota total fabricada por ano. Dessa forma, chegar-se-á à estimativa da frota à gasolina por ano, no período compreendido entre os anos de 1979 e 1990.

Álvares Jr. e Linke (2002) demonstram os fatores de emissão de $\mathrm{CO}_{2}$ para veículos movidos a gasool (mistura de combustíveis utilizada no Brasil, composta por álcool anidro e gasolina) com fabricação anterior a 1992, que são:

-Emissão total $0,175\left(\mathrm{kgCO}_{2} / \mathrm{km}\right)$

-Emissão fóssil $.0,147\left(\mathrm{kgCO}_{2} / \mathrm{km}\right)$

Emissão fóssil é a emissão considerando apenas a gasolina da mistura. Já a emissão total considera as parcelas devido à gasolina e o álcool anidro.

Considerando as emissões da produção do combustível e as emissões próprias da combustão no carro, a redução das emissões de $\mathrm{CO}_{2}$ é da ordem de $80 \%$ quando utilizado um veículo flexpower movido a etanol, comparado com este mesmo veículo movido a gasolina pura (SOARES et al., 2009).

Para Wills (2008) a distância média percorrida anualmente por veículos com mais de onze anos é de 9.500 quilômetros. Multiplicando essa distância média percorrida por esses fatores de emissão será possível chegar à emissão total da frota considerada. 
Tabela 1: Frota brasileira.

\begin{tabular}{l|c|c|c|c|c}
\hline \multicolumn{1}{c}{ Ano } & Automóveis & \multicolumn{2}{c}{ Comerciais leves } & \multicolumn{2}{c}{ Caminhões } \\
\hline 1960 & 56.029 & 114.581 & 126.768 & 12.080 & 309.458 \\
1970 & 1.375 .681 & 647.295 & 422.879 & 48.652 & 2.494 .507 \\
1980 & 7.361 .729 & 1.331 .795 & 1.064 .540 & 142.375 & 9.900 .439 \\
\hline 1990 & 10.796 .993 & 1.684 .320 & 1.238 .376 & 188.458 & 13.908 .147 \\
1991 & 11.046 .230 & 1.713 .695 & 1.239 .672 & 199.009 & 14.198 .606 \\
1992 & 11.258 .551 & 1.745 .017 & 1.222 .967 & 205.476 & 14.432 .011 \\
\hline 1993 & 11.710 .731 & 1.832 .006 & 1.215 .178 & 208.448 & 14.966 .363 \\
1994 & 12.332 .047 & 1.950 .077 & 1.216 .953 & 211.275 & 15.710 .352 \\
1995 & 13.174 .135 & 2.103 .236 & 1.222 .403 & 217.943 & 16.717 .717 \\
\hline 1996 & 13.956 .748 & 2.266 .871 & 1.208 .156 & 222.050 & 17.653 .825 \\
1997 & 14.861 .407 & 2.441 .583 & 1.200 .856 & 224.515 & 18.728 .361 \\
1998 & 15.339 .265 & 2.596 .064 & 1.186 .424 & 228.843 & 19.350 .596 \\
\hline 1999 & 15.587 .503 & 2.645 .686 & 1.164 .540 & 227.501 & 19.625 .230 \\
2000 & 15.961 .778 & 2.784 .614 & 1.152 .937 & 232.502 & 20.131 .831 \\
2001 & 16.509 .717 & 2.891 .056 & 1.148 .456 & 238.263 & 20.787 .492 \\
\hline 2002 & 17.004 .200 & 2.955 .259 & 1.143 .396 & 244.285 & 21.347 .140 \\
2003 & 17.397 .581 & 2.997 .299 & 1.146 .854 & 251.299 & 21.793 .033 \\
2004 & 17.979 .685 & 3.093 .459 & 1.170 .074 & 257.869 & 22.501 .087 \\
\hline 2005 & 18.627 .576 & 3.205 .013 & 1.188 .042 & 263.199 & 23.283 .830 \\
2006 & 19.446 .027 & 3.347 .291 & 1.202 .653 & 273.263 & 24.269 .234 \\
2007 & 20.721 .665 & 3.557 .436 & 1.239 .999 & 287.713 & 25.806 .813 \\
\hline 2008 & 22.245 .767 & 3.950 .712 & 1.301 .375 & 304.909 & 27.802 .763 \\
\hline
\end{tabular}

Fonte: Sindipeças (2009)

Tabela 2: Idades médias dos veículos automotores nacionais por tipo.

\begin{tabular}{ccc}
\hline TIPO/MODELO & QUANTIDADE & IDADE MÉDIA (anos/meses) \\
\hline Automóveis & 22.245 .797 & 9 a. \\
Comerciais leves & 3.950 .712 & 8 a. e $3 \mathrm{~m}$. \\
Caminhões & 1.301 .375 & 10 a. $10 \mathrm{~m}$. \\
Ônibus & 304.909 & 9 a. $6 \mathrm{~m}$. \\
Total & 27.802 .763 & 9 a. \\
\hline
\end{tabular}

Fonte: SINDIPEÇAS (2009)

Tabela 3: Veículos movidos a gasolina fabricados entre 1979 e 1990

\begin{tabular}{ccccccccccccc}
\hline Ano & 1979 & 1980 & 1981 & 1982 & 1983 & 1984 & 1985 & 1986 & 1987 & 1988 & 1989 & 1990 \\
& & & & & & & & & & & \\
$\begin{array}{l}\text { Percentual } \\
\text { à gasolina }\end{array}$ & 99,7 & 72,3 & 71,5 & 61,0 & 11,9 & 5,6 & 4,2 & 8,2 & 6,4 & 12,0 & 39,5 & 86,9 \\
\hline
\end{tabular}

Fonte: ANFAVEA (2009) 
ANÁLISE DA FROTA BRASILEIRA: CURVA DE SUCATEAMENTO E EMISSÕES DE $\mathrm{CO}_{2}$ ACUMULADAS

Inicialmente apurou-se o valor, ano a ano, da frota remanescente movida à gasolina, dos veículos de entrada dos maiores fabricantes nacionais, para o período de 1962 até 1990. Para a definição desse período considerou-se que a vida útil teórica média dos veículos de passeio é de 20 anos, conforme Meyer (2001) e Sindipeças (2008). comentárioVeículos de entrada são aqueles por onde o cliente começa sua trajetória como consumidor de um determinado modelo ou marca.

A seguir, foram traçadas curvas dos valores dos veículos zero quilômetro até o veículo mais antigo de um mesmo modelo, conforme dados constantes na tabela FIPE (2009). Foram considerados os seguintes modelos: Gol, Palio, Uno e Corsa Sedan. Dessa forma, cada uma dessas curvas representa a desvalorização desses veículos ao longo dos anos. Calculou-se também a média ponderada do valor destes veículos, considerando seus preços em agosto de 2009 e o número de unidades produzidas por modelo. Com estas curvas é possível calcular o valor de todos os veículos existentes no mercado para o período de 1962 até 1990. A Tabela 4 apresenta os modelos matemáticos adotados nestes cálculos.

Nesses modelos y é o valor em reais, $\mathrm{x}$ a idade em anos e $e$ o número de Euler. Verifica-se que o veículo que apresenta menor depreciação é o Corsa Sedan, que tem a menor potência exponencial. À partir das curvas do Gol, do Palio, do Uno e do Corsa Sedan calculou-se a média ponderada por quantidade de veículos e chegou-se a uma curva que representa a depreciação média desses quatro modelos. Aplicando a depreciação média ao valor do carro zero quilômetro é possível chegar a um valor médio para cada um desses modelos por ano de fabricação, conforme consta na Tabela 5.

Os valores das células sombreadas foram estimados através dos modelos matemáticos obtidos pelo ajuste exponencial das curvas de cada modelo e indicam os valores desses veículos para os anos não disponíveis na Tabela FIPE.

Para melhor visualização dos resultados a Figura 1 que se segue mostra os dados anteriores em formato gráfico.

A seguir obteve-se o preço médio do carro de passeio movido à gasolina produzido no Brasil, tentando encontrar o valor de um veículo que pudesse ser considerado o "veículo perfil/padrão" da frota. A metodologia adotada para tal procedimento consistiu em calcular a média ponderada do valor dos veículos mais vendidos no país, conforme citado por Quatro Rodas (2009), e mostrado na Tabela 6.

A ponderação na média obtida foi feita utilizando o percentual referente à coluna "Participação nas vendas". Com este calculo chegou-se a um veículo perfil brasileiro zero quilômetro no valor de $\mathrm{R} \$ 33.958,52$. De posse deste valor para o veículo zero quilômetro, combinado com a curva de depreciação já mostrada na Figura 1, chegou-se aos valores da Tabela 7. Essa tabela mostra os preços do veículo padrão/perfil para os anos de 1962 até 2009, para, assim, chegar a um valor único por ano de fabricação.

Para melhor visualização dos resultados da Tabela anterior, a Figura 2, que se segue, mostra esses dados em formato gráfico, onde se destaca a curva "veículo padrão", que representa a evolução do valor do veículo padrão ao longo do tempo. Essa curva representa a depreciação do veículo padrão se levada em conta a depreciação média ponderada calculada anteriormente, porém aplicada a todos os tipos de

Tabela 4: Modelos matemáticos para determinação do valor dos veículos mais vendidos no Brasil

\begin{tabular}{ccc}
\hline VEÍCULO & MODELO MATEMÁTICO \\
\hline Gol & $y=24666 . \mathrm{e}^{-0,0681 x}$ \\
Palio & $y=25218 . \mathrm{e}^{-0,0611 \mathrm{x}}$ \\
Uno & $y=21720 . \mathrm{e}^{-0,064 \mathrm{x}}$ & $\mathrm{y}=25720 . \mathrm{e}^{-0,0496 \mathrm{x}}$
\end{tabular}


Levantamento do perfil e avaliação da frota de veículos de passeio brasileira visando racionalizar as emissões de dióxido de carbono Leonardo Eustáquio Guimarães, Francis Lee

Tabela 5: Valores calculados para os veículos de entrada de fabricantes nacionais e média ponderada destes valores.

\begin{tabular}{|c|c|c|c|c|c|c|}
\hline ANO & IDADE (ANOS) & GOL & PALIO & UNO & CORSA SEDAN & MÉDIA PONDERADA \\
\hline ZERO KM & 0 & $24.666,00$ & $25.218,00$ & $21.720,00$ & $25.720,00$ & $24.441,00$ \\
\hline 2009 & 1 & $23.042,00$ & $23.723,00$ & $20.373,00$ & $24.475,00$ & $22.969,00$ \\
\hline 2008 & 2 & $21.525,00$ & $22.317,00$ & $19.110,00$ & $23.291,00$ & $21.586,00$ \\
\hline 2007 & 3 & $20.108,00$ & $20.994,00$ & $17.926,00$ & $22.164,00$ & $20.288,00$ \\
\hline 2006 & 4 & $18.784,00$ & $19.750,00$ & $16.814,00$ & $21.091,00$ & $19.068,00$ \\
\hline 2005 & 5 & $17.548,00$ & $18.579,00$ & $15.772,00$ & $20.071,00$ & $17.923,00$ \\
\hline 2004 & 6 & $16.393,00$ & $17.478,00$ & $14.794,00$ & $19.100,00$ & $16.847,00$ \\
\hline 2003 & 7 & $15.313,00$ & $16.442,00$ & $13.877,00$ & $18.175,00$ & $15.836,00$ \\
\hline 2002 & 8 & $14.305,00$ & $15.468,00$ & $13.017,00$ & $17.296,00$ & $14.887,00$ \\
\hline 2001 & 9 & $13.363,00$ & $14.551,00$ & $12.210,00$ & $16.459,00$ & $13.995,00$ \\
\hline 2000 & 10 & $12.484,00$ & $13.689,00$ & $11.453,00$ & $15.662,00$ & $13.158,00$ \\
\hline 1999 & 11 & $11.662,00$ & $12.877,00$ & $10.743,00$ & $14.905,00$ & $12.371,00$ \\
\hline 1998 & 12 & $10.894,00$ & $12.114,00$ & $10.077,00$ & $14.183,00$ & $11.631,00$ \\
\hline 1997 & 13 & $10.177,00$ & $11.396,00$ & $9.452,00$ & $13.497,00$ & $10.937,00$ \\
\hline 1996 & 14 & $9.507,00$ & $10.721,00$ & $8.866,00$ & $12.844,00$ & $10.284,00$ \\
\hline 1995 & 15 & $8.881,00$ & $10.085,00$ & $8.316,00$ & $12.222,00$ & $9.671,00$ \\
\hline 1994 & 16 & $8.296,00$ & $9.487,00$ & $7.801,00$ & $11.631,00$ & $9.094,00$ \\
\hline 1993 & 17 & $7.750,00$ & $8.925,00$ & $7.317,00$ & $11.068,00$ & $8.553,00$ \\
\hline 1992 & 18 & $7.240,00$ & $8.396,00$ & $6.864,00$ & $10.533,00$ & $8.044,00$ \\
\hline 1991 & 19 & $6.763,00$ & $7.898,00$ & $6.438,00$ & $10.023,00$ & $7.566,00$ \\
\hline 1990 & 20 & $6.318,00$ & $7.430,00$ & $6.039,00$ & $9.538,00$ & $7.116,00$ \\
\hline 1989 & 21 & $5.902,00$ & $6.990,00$ & $5.665,00$ & $9.076,00$ & $6.694,00$ \\
\hline 1988 & 22 & $5.514,00$ & $6.576,00$ & $5.313,00$ & $8.637,00$ & $6.297,00$ \\
\hline 1987 & 23 & $5.151,00$ & $6.186,00$ & $4.984,00$ & $8.219,00$ & $5.923,00$ \\
\hline 1986 & 24 & $4.812,00$ & $5.819,00$ & $4.675,00$ & $7.821,00$ & $5.572,00$ \\
\hline 1985 & 25 & $4.495,00$ & $5.474,00$ & $4.385,00$ & $7.443,00$ & $5.243,00$ \\
\hline 1984 & 26 & $4.199,00$ & $5.150,00$ & $4.113,00$ & $7.083,00$ & $4.933,00$ \\
\hline 1983 & 27 & $3.922,00$ & $4.845,00$ & $3.858,00$ & $6.740,00$ & $4.641,00$ \\
\hline 1982 & 28 & $3.664,00$ & $4.557,00$ & $3.619,00$ & $6.414,00$ & $4.367,00$ \\
\hline 1981 & 29 & $3.423,00$ & $4.287,00$ & $3.395,00$ & $6.104,00$ & $4.110,00$ \\
\hline 1980 & 30 & $3.198,00$ & $4.033,00$ & $3.184,00$ & $5.808,00$ & $3.867,00$ \\
\hline 1979 & 31 & $2.987,00$ & $3.794,00$ & $2.987,00$ & $5.527,00$ & $3.640,00$ \\
\hline 1978 & 32 & $2.791,00$ & $3.569,00$ & $2.802,00$ & $5.260,00$ & $3.425,00$ \\
\hline 1977 & 33 & $2.607,00$ & $3.358,00$ & $2.628,00$ & $5.005,00$ & $3.224,00$ \\
\hline 1976 & 34 & $2.435,00$ & $3.159,00$ & $2.465,00$ & $4.763,00$ & $3.035,00$ \\
\hline 1975 & 35 & $2.275,00$ & $2.971,00$ & $2.312,00$ & $4.532,00$ & $2.856,00$ \\
\hline 1974 & 36 & $2.125,00$ & $2.795,00$ & $2.169,00$ & $4.313,00$ & $2.689,00$ \\
\hline 1973 & 37 & $1.985,00$ & $2.630,00$ & $2.034,00$ & $4.104,00$ & $2.531,00$ \\
\hline 1972 & 38 & $1.855,00$ & $2.474,00$ & $1.908,00$ & $3.906,00$ & $2.383,00$ \\
\hline 1971 & 39 & $1.732,00$ & $2.327,00$ & $1.790,00$ & $3.717,00$ & $2.244,00$ \\
\hline 1970 & 40 & $1.618,00$ & $2.189,00$ & $1.679,00$ & $3.537,00$ & $2.112,00$ \\
\hline 1969 & 41 & $1.512,00$ & $2.059,00$ & $1.575,00$ & $3.366,00$ & $1.989,00$ \\
\hline 1968 & 42 & $1.412,00$ & $1.937,00$ & $1.477,00$ & $3.203,00$ & $1.873,00$ \\
\hline 1967 & 43 & $1.319,00$ & $1.823,00$ & $1.386,00$ & $3.048,00$ & $1.764,00$ \\
\hline 1966 & 44 & $1.232,00$ & $1.715,00$ & $1.300,00$ & $2.900,00$ & $1.661,00$ \\
\hline 1965 & 45 & $1.151,00$ & $1.613,00$ & $1.219,00$ & $2.760,00$ & $1.564,00$ \\
\hline 1964 & 46 & $1.076,00$ & $1.517,00$ & $1.144,00$ & $2.627,00$ & $1.473,00$ \\
\hline 1963 & 47 & $1.005,00$ & $1.427,00$ & $1.073,00$ & $2.499,00$ & $1.388,00$ \\
\hline 1962 & 48 & 939,00 & $1.343,00$ & $1.006,00$ & $2.378,00$ & $1.307,00$ \\
\hline
\end{tabular}

Fonte: FIPE (2009) e elaboração própria.

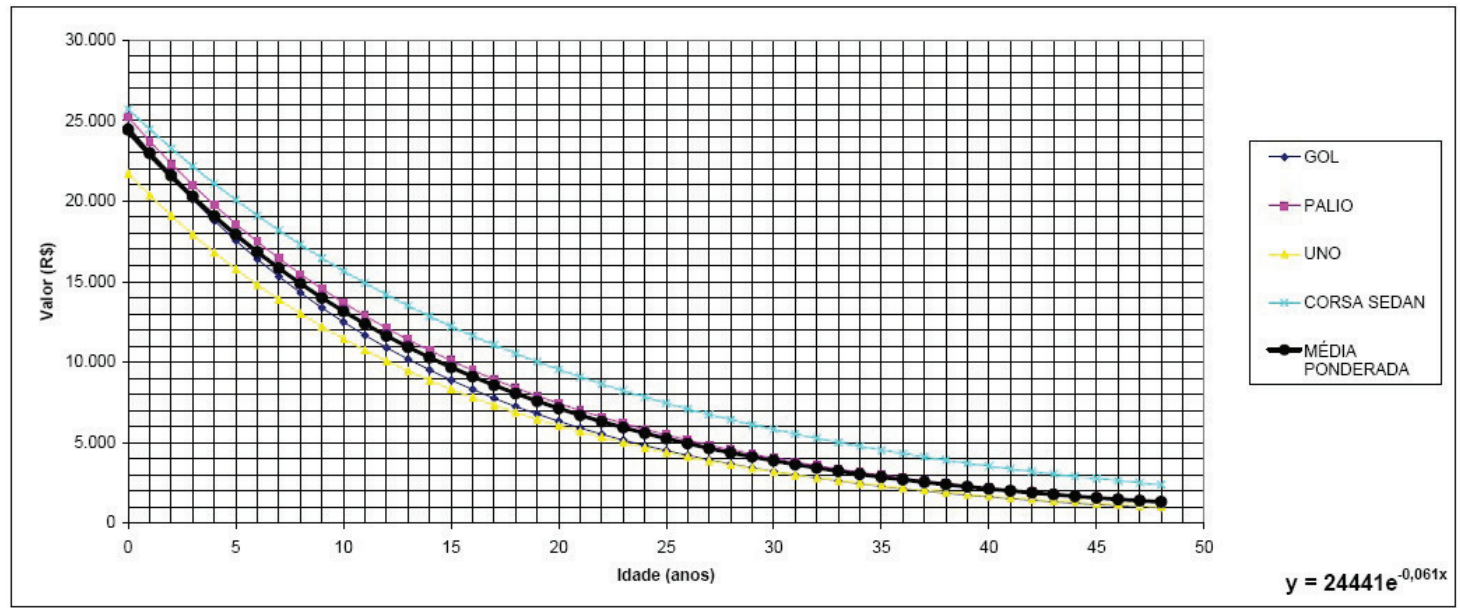

Figura 1: Curvas de depreciação dos quatro modelos de veículos mais vendidos no Brasil. 
veículos, e não somente aos básicos.

Para avaliar a frota de veículos brasileiros é preciso calcular o número de veículos existentes, ou seja, quantificá-la. Antes deste fechamento foi necessário fazer o ajuste da frota excluindo os utilitários leves, os caminhões e os ônibus. Excluíram-se também os veículos a álcool. Assim, chegou-se ao número de veículos de passeio, à gasolina, produzidos no Brasil, com vinte anos ou mais, como se mostra na Tabela 8.

Após conhecer o número de veículos que compõem a frota e um valor que represente um veículo padrão para a frota, é possível chegar à avaliação estimada da frota de veículos brasileiros, à gasolina, com idade maior que 20 anos, conforme mostrado na Tabela 9 a seguir.

Tabela 6: Quantitativos e valores adotados para o cálculo do preço do veículo padrão

\begin{tabular}{|c|c|c|c|c|c|}
\hline ITEM & VEÍCULO & PREÇO & VENDIDOS & $\begin{array}{l}\text { PARTICIPAÇAO } \\
\text { NAS VENDAS }(\%)\end{array}$ & $\begin{array}{c}\text { SUB-TOTALPOR } \\
\text { MODELO DE VEÍCULO }\end{array}$ \\
\hline 1 & GOL & $26.782,00$ & 285.949 & 11,23 & $7.658 .286 .118,00$ \\
\hline 2 & PALIO & $26.700,00$ & 197.224 & 7,75 & $5.265 .880 .800,00$ \\
\hline 3 & UNO & $23.204,00$ & 141.873 & 5,57 & $3.292 .021 .092,00$ \\
\hline 4 & CORSA SEDAN & $27.139,00$ & 131.730 & 5,17 & $3.575 .020 .470,00$ \\
\hline 5 & CELTA & $24.900,00$ & 130.387 & 5,12 & $3.246 .636 .300,00$ \\
\hline 6 & FOX/CROSSFOX & $32.042,00$ & 115.071 & 4,52 & 3.687.104.982,00 \\
\hline 7 & SIENA & $30.390,00$ & 95.307 & 3,74 & $2.896 .379 .730,00$ \\
\hline 8 & CIVIC & $63.821,00$ & 67.703 & 2,66 & $4.320 .873 .163,00$ \\
\hline 9 & KA & $28.029,00$ & 64.887 & 2,55 & $1.818 .717 .723,00$ \\
\hline 10 & FIESTA HATCH & $32.815,00$ & 58.828 & 2,31 & $1.930 .440 .820,00$ \\
\hline 11 & PRISMA & $29.442,00$ & 50.598 & 1,99 & $1.489 .706 .316,00$ \\
\hline 12 & CORSA & $34.470,00$ & 47.309 & 1,86 & $1.630 .741 .230,00$ \\
\hline 13 & COROLLA & $59.834,00$ & 45.640 & 1,79 & $2.730 .823 .760,00$ \\
\hline 15 & HONDA FIT & $51.973,00$ & 40.512 & 1,59 & $2.105 .530 .176,00$ \\
\hline 16 & SANDERO & $30.555,00$ & 39.631 & 1,56 & $1.210 .925 .205,00$ \\
\hline 17 & PUNTO & $38.299,00$ & 38.576 & 1,52 & $1.477 .422 .224,00$ \\
\hline 18 & FIESTA SEDAN & $32.928,00$ & 37.934 & 1,49 & $1.249 .090 .752,00$ \\
\hline 19 & RENAULT LOGAN & $29.884,00$ & 36.598 & 1,44 & $1.093 .694 .632,00$ \\
\hline 20 & $\mathrm{C} 3$ & $39.882,00$ & 35.844 & 1,41 & $1.429 .530 .408,00$ \\
\hline 21 & PEUGEOT 206 & $32.032,00$ & 33.137 & 1,30 & $1.061 .444 .384,00$ \\
\hline 22 & PALIO WEEKEND & $41.865,00$ & 30.392 & 1,19 & $1.272 .361 .080,00$ \\
\hline 23 & FIAT IDEA & $41.901,00$ & 27.011 & 1,06 & $1.131 .787 .911,00$ \\
\hline 24 & GM VECTRA & $52.373,00$ & 26.619 & 1,05 & $1.394 .116 .887,00$ \\
\hline 25 & GM ASTRA HATCH & $43.255,00$ & 25.355 & 1,00 & $1.096 .730 .525,00$ \\
\hline 26 & GM MERIVA & $44.742,00$ & 24.363 & 0,96 & $1.090 .049 .346,00$ \\
\hline 27 & VW POLO SEDAN & $47.116,00$ & 24.285 & 0,95 & $1.144 .212 .060,00$ \\
\hline 28 & VW SPACEFOX & $47.312,00$ & 22.220 & 0,87 & $1.051 .272 .640,00$ \\
\hline 32 & VW POLO HATCH & $44.129,00$ & 18.341 & 0,72 & $809.369 .989,00$ \\
\hline 35 & CITROËN C4 PALLAS & $62.481,00$ & 17.948 & 0,71 & $1.121 .408 .988,00$ \\
\hline 36 & VW PARATI & $39.245,00$ & 17.766 & 0,70 & $697.226 .670,00$ \\
\hline 37 & VW GOLF & $52.332,00$ & 17.265 & 0,68 & $903.511 .980,00$ \\
\hline 38 & FIAT STILO & $55.119,00$ & 16.326 & 0,64 & $899.872 .794,00$ \\
\hline 40 & FORD FOCUS HATCH & $62.936,00$ & 13.181 & 0,52 & $829.559 .416,00$ \\
\hline 41 & PEUGEOT 207 HATCH & $36.125,00$ & 12.990 & 0,51 & $469.263 .750,00$ \\
\hline 42 & GM VECTRA GT & $55.447,00$ & 12.948 & 0,51 & $717.927 .756,00$ \\
\hline 43 & PEUGEOT 307 HATCH & $52.481,00$ & 12.938 & 0,51 & $678.999 .178,00$ \\
\hline \multirow[t]{2}{*}{45} & RENAULT CLIO HATCH & $28.503,00$ & 11.397 & 0,45 & $324.848 .691,00$ \\
\hline & TOTAIS & & 2.026 .083 & 79,59 & $68.802 .789 .946,00$ \\
\hline
\end{tabular}

Fonte: FIPE (2009), Quatro Rodas (2009) e elaboração própria. 
Tabela 7: Valores dos veículos padrão com idades entre 1962 e 2009.

\begin{tabular}{|c|c|c|c|c|c|c|c|}
\hline ANO & $\begin{array}{l}\text { IDADE } \\
\text { (ANOS) }\end{array}$ & GOL & PALIO & UNO & $\begin{array}{l}\text { CORSA } \\
\text { SEDAN }\end{array}$ & $\begin{array}{c}\text { MÉDIA } \\
\text { PONDERADA }\end{array}$ & $\begin{array}{l}\text { VEÍCULO } \\
\text { PADRÃO }\end{array}$ \\
\hline $0 \mathrm{Km}$ & 0 & 24666 & 25218 & 21720 & 25720 & 24441 & $\mathrm{R} \$ 33.958,52$ \\
\hline 2009 & 1 & 23042 & 23723 & 20373 & 24475 & 22969 & $\mathrm{R} \$ 31.948,96$ \\
\hline 2008 & 2 & 21525 & 22317 & 19110 & 23291 & 21586 & $\mathrm{R} \$ 30.058,33$ \\
\hline 2007 & 3 & 20108 & 20994 & 17926 & 22164 & 20288 & $\mathrm{R} \$ 28.279,57$ \\
\hline 2006 & 4 & 18784 & 19750 & 16814 & 21091 & 19068 & $\mathrm{R} \$ 26.606,08$ \\
\hline 2005 & 5 & 17548 & 18579 & 15772 & 20071 & 17923 & $\mathrm{R} \$ 25.031,62$ \\
\hline 2004 & 6 & 16393 & 17478 & 14794 & 19100 & 16847 & $\mathrm{R} \$ 23.550,33$ \\
\hline 2003 & 7 & 15313 & 16442 & 13877 & 18175 & 15836 & $\mathrm{R} \$ 22.156,70$ \\
\hline 2002 & 8 & 14305 & 15468 & 13017 & 17296 & 14887 & $\mathrm{R} \$ 20.845,54$ \\
\hline 2001 & 9 & 13363 & 14551 & 12210 & 16459 & 13995 & $\mathrm{R} \$ 19.611,96$ \\
\hline 2000 & 10 & 12484 & 13689 & 11453 & 15662 & 13158 & $\mathrm{R} \$ 18.451,39$ \\
\hline 1999 & 11 & 11662 & 12877 & 10743 & 14905 & 12371 & $\mathrm{R} \$ 17.359,50$ \\
\hline 1998 & 12 & 10894 & 12114 & 10077 & 14183 & 11631 & $\mathrm{R} \$ 16.332,22$ \\
\hline 1997 & 13 & 10177 & 11396 & 9452 & 13497 & 10937 & $\mathrm{R} \$ 15.365,73$ \\
\hline 1996 & 14 & 9507 & 10721 & 8866 & 12844 & 10284 & $\mathrm{R} \$ 14.456,44$ \\
\hline 1995 & 15 & 8881 & 10085 & 8316 & 12222 & 9671 & $\mathrm{R} \$ 13.600,95$ \\
\hline 1994 & 16 & 8296 & 9487 & 7801 & 11631 & 9094 & $\mathrm{R} \$ 12.796,09$ \\
\hline 1993 & 17 & 7750 & 8925 & 7317 & 11068 & 8553 & $\mathrm{R} \$ 12.038,86$ \\
\hline 1992 & 18 & 7240 & 8396 & 6864 & 10533 & 8044 & $\mathrm{R} \$ 11.326,44$ \\
\hline 1991 & 19 & 6763 & 7898 & 6438 & 10023 & 7566 & $\mathrm{R} \$ 10.656,18$ \\
\hline 1990 & 20 & 6318 & 7430 & 6039 & 9538 & 7116 & $\mathrm{R} \$ 10.025,58$ \\
\hline 1989 & 21 & 5902 & 6990 & 5665 & 9076 & 6694 & $\mathrm{R} \$ 9.432,30$ \\
\hline 1988 & 22 & 5514 & 6576 & 5313 & 8637 & 6297 & $\mathrm{R} \$ 8.874,13$ \\
\hline 1987 & 23 & 5151 & 6186 & 4984 & 8219 & 5923 & $\mathrm{R} \$ 8.348,98$ \\
\hline 1986 & 24 & 4812 & 5819 & 4675 & 7821 & 5572 & $\mathrm{R} \$ 7.854,92$ \\
\hline 1985 & 25 & 4495 & 5474 & 4385 & 7443 & 5243 & $\mathrm{R} \$ 7.390,09$ \\
\hline 1984 & 26 & 4199 & 5150 & 4113 & 7083 & 4933 & $\mathrm{R} \$ 6.952,77$ \\
\hline 1983 & 27 & 3922 & 4845 & 3858 & 6740 & 4641 & $\mathrm{R} \$ 6.541,33$ \\
\hline 1982 & 28 & 3664 & 4557 & 3619 & 6414 & 4367 & $\mathrm{R} \$ 6.154,23$ \\
\hline 1981 & 29 & 3423 & 4287 & 3395 & 6104 & 4110 & $\mathrm{R} \$ 5.790,04$ \\
\hline 1980 & 30 & 3198 & 4033 & 3184 & 5808 & 3867 & $\mathrm{R} \$ 5.447,41$ \\
\hline 1979 & 31 & 2987 & 3794 & 2987 & 5527 & 3640 & $\mathrm{R} \$ 5.125,05$ \\
\hline 1978 & 32 & 2791 & 3569 & 2802 & 5260 & 3425 & $\mathrm{R} \$ 4.821,76$ \\
\hline 1977 & 33 & 2607 & 3358 & 2628 & 5005 & 3224 & $\mathrm{R} \$ 4.536,43$ \\
\hline 1976 & 34 & 2435 & 3159 & 2465 & 4763 & 3035 & $\mathrm{R} \$ 4.267,98$ \\
\hline 1975 & 35 & 2275 & 2971 & 2312 & 4532 & 2856 & $\mathrm{R} \$ 4.015,41$ \\
\hline 1974 & 36 & 2125 & 2795 & 2169 & 4313 & 2689 & $\mathrm{R} \$ 3.777,79$ \\
\hline 1973 & 37 & 1985 & 2630 & 2034 & 4104 & 2531 & $\mathrm{R} \$ 3.554,23$ \\
\hline 1972 & 38 & 1855 & 2474 & 1908 & 3906 & 2383 & $\mathrm{R} \$ 3.343,91$ \\
\hline 1971 & 39 & 1732 & 2327 & 1790 & 3717 & 2244 & $\mathrm{R} \$ 3.146,03$ \\
\hline 1970 & 40 & 1618 & 2189 & 1679 & 3537 & 2112 & $\mathrm{R} \$ 2.959,85$ \\
\hline 1969 & 41 & 1512 & 2059 & 1575 & 3366 & 1989 & $\mathrm{R} \$ 2.784,70$ \\
\hline 1968 & 42 & 1412 & 1937 & 1477 & 3203 & 1873 & $\mathrm{R} \$ 2.619,91$ \\
\hline 1967 & 43 & 1319 & 1823 & 1386 & 3048 & 1764 & $\mathrm{R} \$ 2.464,87$ \\
\hline 1966 & 44 & 1232 & 1715 & 1300 & 2900 & 1661 & $\mathrm{R} \$ 2.319,01$ \\
\hline 1965 & 45 & 1151 & 1613 & 1219 & 2760 & 1564 & $\mathrm{R} \$ 2.181,78$ \\
\hline 1964 & 46 & 1076 & 1517 & 1144 & 2627 & 1473 & $\mathrm{R} \$ 2.052,67$ \\
\hline 1963 & 47 & 1005 & 1427 & 1073 & 2499 & 1388 & $\mathrm{R} \$ 1.931,20$ \\
\hline 1962 & 48 & 939 & 1343 & 1006 & 2378 & 1307 & $\mathrm{R} \$ 1.816,91$ \\
\hline
\end{tabular}

Fonte: FIPE (2009) e elaboração própria. 


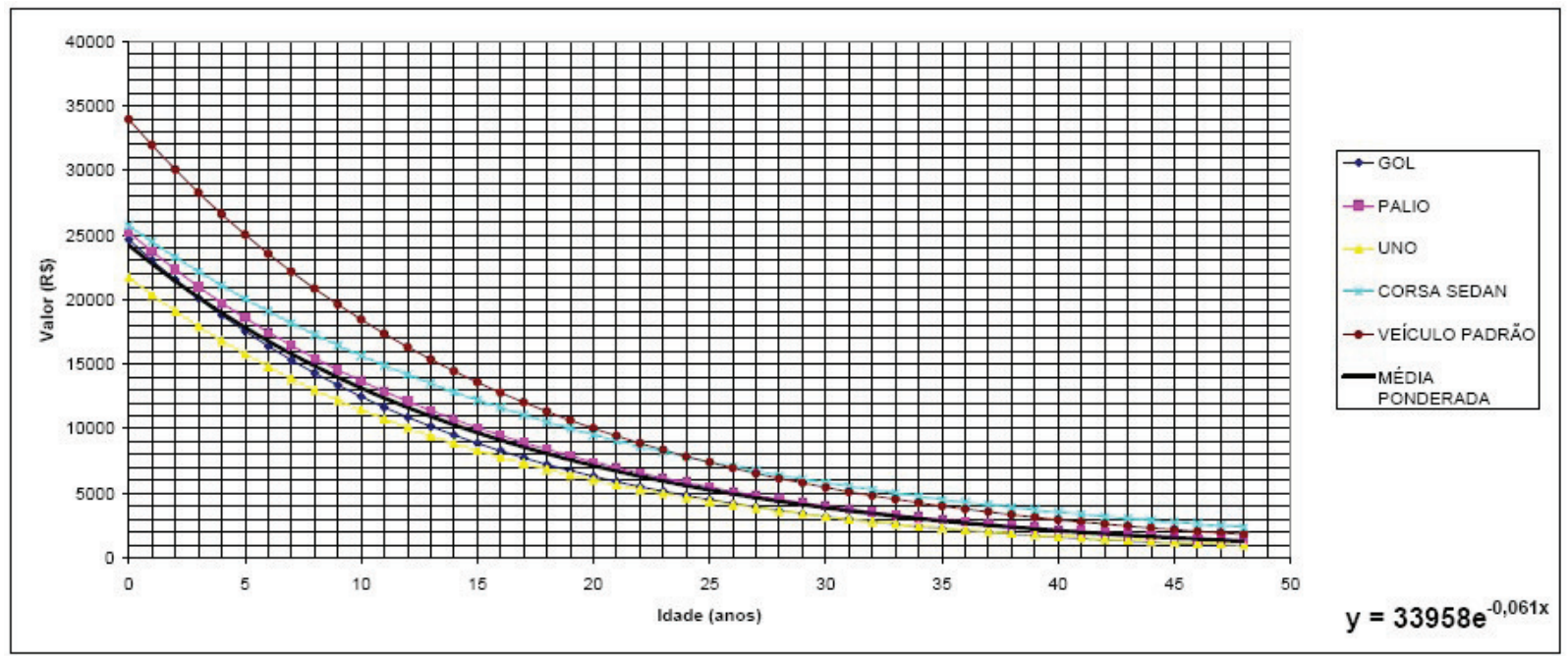

Figura 2 - Curva de depreciação do veículo padrão

Tabela 8: Ajustes para cálculo da frota de veículos de passeio, movidos a gasolina, fabricados entre 1962 e 1990.

\begin{tabular}{|c|c|c|c|c|c|}
\hline $\begin{array}{c}\text { ANO } \\
\text { FABRICAÇÃO }\end{array}$ & $\begin{array}{l}\text { IDADE } \\
\text { (ANOS) }\end{array}$ & $\begin{array}{l}\text { FROTA LEVE COM } \\
\text { COMERCIAIS (un.) }\end{array}$ & $\begin{array}{l}\text { FROTA PASSEIO } \\
\text { ESTIMADA (un.) }\end{array}$ & $\begin{array}{l}\text { PERCENTUAL } \\
\text { À GASOLINA }\end{array}$ & $\begin{array}{l}\text { FROTA PASSEIO } \\
\text { À GASOLINA (un.) }\end{array}$ \\
\hline 1990 & 20 & 474.911,0 & $379.989,6$ & 86,9 & $330.134,9$ \\
\hline 1989 & 21 & $490.157,0$ & $392.188,3$ & 39,5 & $154.914,4$ \\
\hline 1988 & 22 & $360.362,0$ & $288.335,7$ & 12,0 & $34.600,3$ \\
\hline 1987 & 23 & $204.500,0$ & $163.626,2$ & 6,4 & $10.439,3$ \\
\hline 1986 & 24 & $305.362,0$ & $244.328,7$ & 8,2 & $19.912,8$ \\
\hline 1985 & 25 & $141.832,0$ & $113.483,7$ & 4,2 & $4.811,7$ \\
\hline 1984 & 26 & $85.597,0$ & $68.488,5$ & 5,6 & $3.821,7$ \\
\hline 1983 & 27 & $64.594,0$ & $51.683,5$ & 11,9 & $6.165,8$ \\
\hline 1982 & 28 & $41.905,0$ & $33.529,4$ & 61,0 & $20.456,3$ \\
\hline 1981 & 29 & $30.146,0$ & $24.120,7$ & 71,5 & $17.246,9$ \\
\hline 1980 & 30 & $31.486,0$ & $25.192,8$ & 72,3 & $18.207,2$ \\
\hline 1979 & 31 & $20.569,0$ & $16.457,8$ & 99,7 & $16.401,8$ \\
\hline 1978 & 32 & $13.078,0$ & $10.464,1$ & 100,0 & $10.464,1$ \\
\hline 1977 & 33 & $8.156,0$ & $6.525,8$ & 100,0 & $6.525,8$ \\
\hline 1976 & 34 & $5.024,0$ & $4.019,8$ & 100,0 & $4.019,8$ \\
\hline 1975 & 35 & $3.096,0$ & $2.477,2$ & 100,0 & $2.477,2$ \\
\hline 1974 & 36 & $1.912,0$ & $1.529,8$ & 100,0 & $1.529,8$ \\
\hline 1973 & 37 & $1.115,0$ & 892,1 & 100,0 & 892,1 \\
\hline 1972 & 38 & 539,0 & 431,3 & 100,0 & 431,3 \\
\hline 1971 & 39 & 265,0 & 212,0 & 100,0 & 212,0 \\
\hline 1970 & 40 & 155,0 & 124,0 & 100,0 & 124,0 \\
\hline 1969 & 41 & 108,0 & 86,4 & 100,0 & 86,4 \\
\hline 1968 & 42 & 130,0 & 104,0 & 100,0 & 104,0 \\
\hline 1967 & 43 & 27,0 & 21,6 & 100,0 & 21,6 \\
\hline 1966 & 44 & 17,0 & 13,6 & 100,0 & 13,6 \\
\hline 1965 & 45 & 8,0 & 6,4 & 100,0 & 6,4 \\
\hline 1964 & 46 & 4,0 & 3,2 & 100,0 & 3,2 \\
\hline 1963 & 47 & 3,0 & 2,4 & 100,0 & 2,4 \\
\hline 1962 & 48 & 4,0 & 3,2 & 100,0 & 3,2 \\
\hline TOTAIS & & $2.285 .062,0$ & $1.828 .341,9$ & & $664.030,2$ \\
\hline
\end{tabular}

Fonte: Elaboração própria. 
EMISSÕES DE CO2 DA FROTA BRASILEIRAA PARTIR DE 20 ANOS DE CIRCULAÇÃO

Para cálculo das emissões de $\mathrm{CO}_{2}$ aplicouse a metodologia de cálculo de Álvares Jr. e Linke (2002). Os autores apresentam duas formas diferentes de executar o inventário de emissões: as metodologias top-down e botton-up.

$\mathrm{O}$ método top-down utiliza a quantidade de combustível queimada pela frota para quantificar as emissões. É considerado mais preciso e, portanto, deve ser utilizado sempre que possível. Como não é possível mensurar a quantidade de combustível utili- zada somente por essa frota, foi necessário o uso da metodologia botton-up, que utiliza a quilometragem média e os fatores de emissão para chegar aos gases emitidos pela frota.

Multiplicando o número de veículos (Tabela 8), a quilometragem média anual percorrida de 9500 quilômetros (Wills, 2008) e o fator de emissão de $\mathrm{CO}_{2}$, foi possível calcular as emissões da frota investigada (Tabela 10).

Pela Tabela anterior percebe-se que a emissão total de $\mathrm{CO}_{2}$ da frota estudada é de 927.318 toneladas de $\mathrm{CO}_{2}$. Verifica-se que $73 \%$ das emissões estão relacionadas a veículos 1989 e 1990, que também

Tabela 9: Valor da frota de veículos brasileiros de passeio movidos a gasolina remanescentes de 1962 a 1990.

\begin{tabular}{|c|c|c|c|c|}
\hline ANO & $\begin{array}{l}\text { IDADE } \\
\text { (ANOS) }\end{array}$ & $\begin{array}{c}\text { FROTAA } \\
\text { GASOLINA (un.) }\end{array}$ & $\begin{array}{l}\text { VALOR POR } \\
\text { IDADE (R\$) }\end{array}$ & $\begin{array}{l}\text { SUBTOTAL } \\
\text { (R\$) }\end{array}$ \\
\hline 1990 & 20 & $330.134,92$ & $10.025,58$ & $3.309 .794 .396,49$ \\
\hline 1989 & 21 & $154.914,38$ & $9.432,30$ & $1.461 .198 .832,89$ \\
\hline 1988 & 22 & $34.600,28$ & $8.874,13$ & $307.047 .300,16$ \\
\hline 1987 & 23 & $10.439,35$ & $8.348,98$ & $87.157 .963,89$ \\
\hline 1986 & 24 & $19.912,79$ & $7.854,92$ & $156.413 .315,45$ \\
\hline 1985 & 25 & $4.811,71$ & $7.390,09$ & $35.558 .975,66$ \\
\hline 1984 & 26 & $3.821,66$ & $6.952,77$ & $26.571 .124,70$ \\
\hline 1983 & 27 & $6.165,84$ & $6.541,33$ & $40.332 .751,84$ \\
\hline 1982 & 28 & $20.456,26$ & $6.154,23$ & $125.892 .581,18$ \\
\hline 1981 & 29 & $17.246,92$ & $5.790,04$ & $99.860 .429,59$ \\
\hline 1980 & 30 & $18.207,24$ & $5.447,41$ & $99.182 .268,13$ \\
\hline 1979 & 31 & $16.401,77$ & $5.125,05$ & $84.059 .841,27$ \\
\hline 1978 & 32 & $10.464,07$ & $4.821,76$ & $50.455 .294,74$ \\
\hline 1977 & 33 & $6.525,84$ & $4.536,43$ & $29.604 .018,58$ \\
\hline 1976 & 34 & $4.019,84$ & $4.267,98$ & $17.156 .595,75$ \\
\hline 1975 & 35 & $2.477,20$ & $4.015,41$ & $9.946 .962,40$ \\
\hline 1974 & 36 & $1.529,84$ & $3.777,79$ & $5.779 .435,87$ \\
\hline 1973 & 37 & 892,14 & $3.554,24$ & $3.170 .884,80$ \\
\hline 1972 & 38 & 431,27 & $3.343,91$ & $1.442 .123,32$ \\
\hline 1971 & 39 & 212,03 & $3.146,03$ & $667.064,06$ \\
\hline 1970 & 40 & 124,02 & $2.959,85$ & $367.080,58$ \\
\hline 1969 & 41 & 86,41 & $2.784,70$ & $240.636,50$ \\
\hline 1968 & 42 & 104,02 & $2.619,91$ & $272.514,20$ \\
\hline 1967 & 43 & 21,60 & $2.464,87$ & $53.249,75$ \\
\hline 1966 & 44 & 13,60 & $2.319,01$ & $31.543,57$ \\
\hline 1965 & 45 & 6,40 & $2.181,78$ & $13.965,61$ \\
\hline 1964 & 46 & 3,20 & $2.052,67$ & $6.569,58$ \\
\hline 1963 & 47 & 2,40 & $1.931,20$ & $4.635,61$ \\
\hline 1962 & 48 & 3,20 & $1.816,91$ & $5.815,06$ \\
\hline \multicolumn{2}{|c|}{ VALOR TOTAL } & & & $5.952 .288 .171,22$ \\
\hline
\end{tabular}

Fonte: Elaboração própria. 


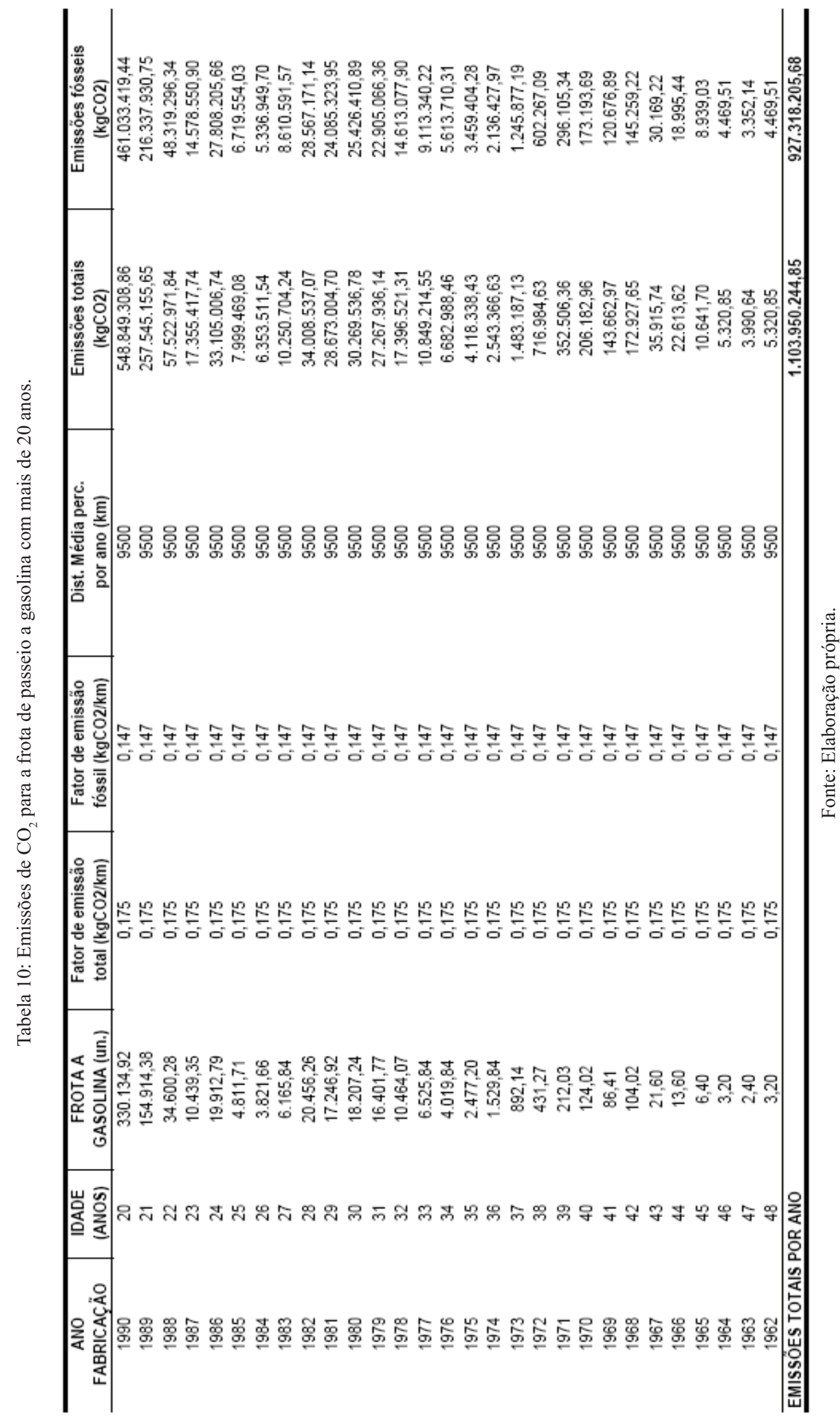

Sociedade \& Natureza, Uberlândia, 22 (3): 577-592, dez. 2010 
Levantamento do perfil e avaliação da frota de veículos de passeio brasileira visando racionalizar as emissões de dióxido de carbono Leonardo Eustáquio Guimarães, Francis Lee

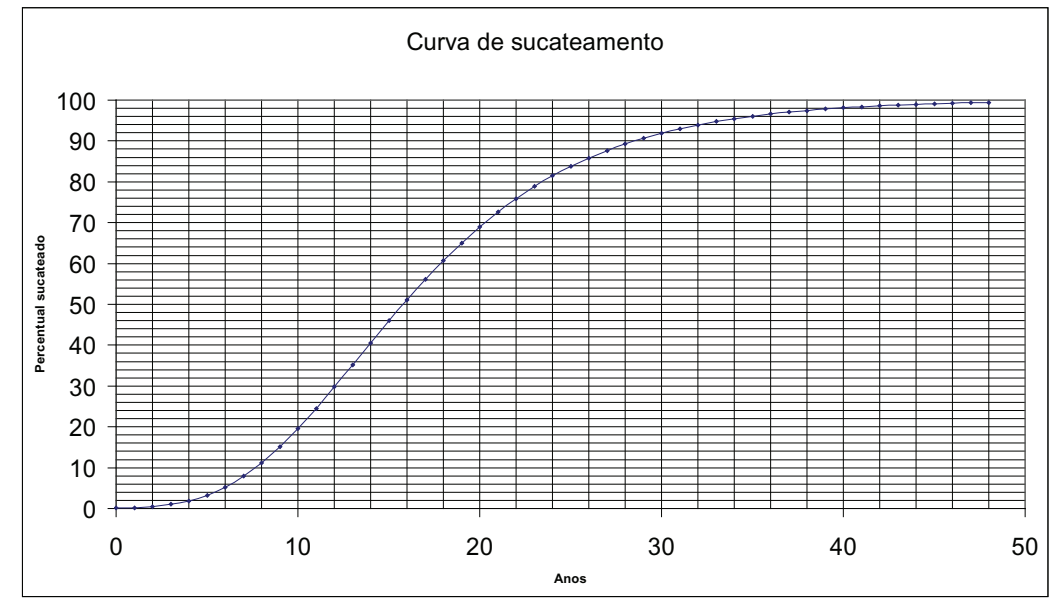

Figura 3: Curva de sucateamento. Fonte: BORBA, 2008.

Tabela 11: Emissões de $\mathrm{CO}_{2}$ acumuladas da data atual até o ano de 2050.

\begin{tabular}{|c|c|c|}
\hline ANO & $\begin{array}{c}\text { Emissőes totais } \\
\text { ACUMULADA (kgCO2) }\end{array}$ & $\begin{array}{c}\text { Emissões fósseis } \\
\text { ACUMULADA (kgCO2) }\end{array}$ \\
\hline 2009 & 1.103 .950 .245 & 927.318 .206 \\
\hline 2010 & 2.074 .799 .036 & 1.742 .831 .190 \\
\hline 2011 & 2.926 .441 .907 & 2.458 .211 .202 \\
\hline 2012 & 3.671 .860 .789 & 3.084 .363 .063 \\
\hline 2013 & 4.323 .038 .386 & 3.631 .352 .244 \\
\hline 2014 & 4.890.923.987 & 4.108.376.149 \\
\hline 2015 & 5.385 .438 .072 & 4.523 .767 .981 \\
\hline 2016 & 5.815 .504 .824 & 4.885 .024 .052 \\
\hline 2017 & 6.189 .103 .600 & 5.198 .847 .024 \\
\hline 2018 & 6.513 .332 .250 & 5.471 .199 .090 \\
\hline 2019 & 6.794 .476 .799 & 5.707 .360 .511 \\
\hline 2020 & 7.038 .083 .454 & 5.911 .990 .101 \\
\hline 2021 & 7.249 .029 .992 & 6.089 .185 .193 \\
\hline 2022 & 7.431 .594 .553 & 6.242 .539 .425 \\
\hline 2023 & 7.589 .520 .528 & 6.375 .197 .244 \\
\hline 2024 & 7.726 .076 .788 & 6.489 .904 .502 \\
\hline 2025 & 7.844 .112 .889 & 6.589 .054 .827 \\
\hline 2026 & 7.946 .109 .160 & 6.674 .731 .695 \\
\hline 2027 & 8.034 .221 .782 & 6.748 .746 .297 \\
\hline 2028 & 8.110 .323 .082 & 6.812 .671 .389 \\
\hline 2029 & 8.176 .037 .366 & 6.867 .871 .387 \\
\hline 2030 & 8.232 .772 .620 & 6.915 .529 .000 \\
\hline 2031 & 8.281 .748 .464 & 6.956 .668 .709 \\
\hline 2032 & 8.324 .020 .712 & 6.992 .177 .398 \\
\hline 2033 & 8.360 .502 .900 & 7.022 .822 .436 \\
\hline 2034 & 8.391.985.098 & 7.049 .267 .482 \\
\hline 2035 & 8.419 .150 .338 & 7.072 .086 .284 \\
\hline 2036 & 8.442 .588 .916 & 7.091 .774 .689 \\
\hline 2037 & 8.462 .810 .838 & 7.108 .761 .104 \\
\hline 2038 & 8.480 .256 .629 & 7.123 .415 .568 \\
\hline 2039 & 8.495 .306 .720 & 7.136 .057 .645 \\
\hline 2040 & 8.508 .289 .586 & 7.146 .963 .253 \\
\hline 2041 & 8.519 .488 .794 & 7.156 .370 .587 \\
\hline 2042 & 8.529 .149 .109 & 7.164 .485 .252 \\
\hline 2043 & 8.537 .481 .783 & 7.171 .484 .698 \\
\hline 2044 & 8.544 .669 .120 & 7.177 .522 .061 \\
\hline 2045 & 8.550 .868 .432 & 7.182 .729 .483 \\
\hline 2046 & 8.556 .215 .454 & 7.187 .220 .982 \\
\hline 2047 & 8.560 .827 .296 & 7.191 .094 .929 \\
\hline 2048 & 8.564 .804 .992 & 7.194 .436 .193 \\
\hline 2049 & 8.568 .235 .704 & 7.197.317.991 \\
\hline 2050 & 8.571 .194 .623 & 7.199 .803 .483 \\
\hline
\end{tabular}

Fonte: Elaboração própria. 
Levantamento do perfil e avaliação da frota de veículos de passeio brasileira visando racionalizar as emissões de dióxido de carbono Leonardo Eustáquio Guimarães, Francis Lee

Tabela 12: Investimento recuperado com o sucateamento da frota brasileira de veículos de passeio, movidos à gasolina, vendidos de 1962 à 1990

\begin{tabular}{|c|c|c|c|c|c|}
\hline $\begin{array}{c}\mathrm{t} \\
\text { bricação }\end{array}$ & $\begin{array}{l}\text { Idade } \\
\text { (anos) }\end{array}$ & $\begin{array}{l}\text { Emissões fós- } \\
\text { seis (kgCO2) }\end{array}$ & $\begin{array}{l}\text { Retorno devido } \\
\text { créditos carbono }\end{array}$ & $\begin{array}{l}\text { Custo da frota } \\
\text { a ser sucateada }\end{array}$ & $\begin{array}{c}\text { Investimento } \\
\text { recuperado }\end{array}$ \\
\hline 1990 & 20 & 3.636 .561 .750 & $\mathrm{R} \$ 129.799 .071$ & $\mathrm{R} \$ 3.309 .794 .396$ & $3,92 \%$ \\
\hline 1989 & 21 & 1.687.322.218 & $\mathrm{R} \$ 60.225 .254$ & $\mathrm{R} \$ 1.461 .198 .833$ & $4,12 \%$ \\
\hline 1988 & 22 & 373.196 .539 & $\mathrm{R} \$ 13.320 .429$ & $\mathrm{R} \$ 307.047 .300$ & $4,34 \%$ \\
\hline 1987 & 23 & 111.646 .911 & $\mathrm{R} \$ 3.984 .991$ & $\mathrm{R} \$ 87.157 .964$ & $4,57 \%$ \\
\hline 1986 & 24 & 211.403 .575 & $\mathrm{R} \$ 7.545 .586$ & $\mathrm{R} \$ 156.413 .315$ & $4,82 \%$ \\
\hline 1985 & 25 & 50.759 .212 & $\mathrm{R} \$ 1.811 .738$ & $\mathrm{R} \$ 35.558 .976$ & $5,10 \%$ \\
\hline 1984 & 26 & 40.093 .570 & $\mathrm{R} \$ 1.431 .052$ & $\mathrm{R} \$ 26.571 .125$ & $5,39 \%$ \\
\hline 1983 & 27 & 64.379 .099 & $\mathrm{R} \$ 2.297 .870$ & $\mathrm{R} \$ 40.332 .752$ & $5,70 \%$ \\
\hline 1982 & 28 & 212.710 .869 & $\mathrm{R} \$ 7.592 .246$ & $\mathrm{R} \$ 125.892 .581$ & $6,03 \%$ \\
\hline 1981 & 29 & 178.701 .558 & $\mathrm{R} \$ 6.378 .359$ & $\mathrm{R} \$ 99.860 .430$ & $6,39 \%$ \\
\hline 1980 & 30 & 188.072 .211 & $\mathrm{R} \$ 6.712 .824$ & $\mathrm{R} \$ 99.182 .268$ & $6,77 \%$ \\
\hline 1979 & 31 & 168.972 .826 & $\mathrm{R} \$ 6.031 .113$ & $\mathrm{R} \$ 84.059 .841$ & $7,17 \%$ \\
\hline 1978 & 32 & 107.554 .901 & $\mathrm{R} \$ 3.838 .936$ & $\mathrm{R} \$ 50.455 .295$ & $7,61 \%$ \\
\hline 1977 & 33 & 66.943 .039 & $\mathrm{R} \$ 2.389 .384$ & $\mathrm{R} \$ 29.604 .019$ & $8,07 \%$ \\
\hline 1976 & 34 & 41.165 .636 & $\mathrm{R} \$ 1.469 .317$ & $\mathrm{R} \$ 17.156 .596$ & $8,56 \%$ \\
\hline 1975 & 35 & 25.330 .562 & $\mathrm{R} \$ 904.119$ & $\mathrm{R} \$ 9.946 .962$ & $9,09 \%$ \\
\hline 1974 & 36 & 15.623 .497 & $\mathrm{R} \$ 557.646$ & $\mathrm{R} \$ 5.779 .436$ & $9,65 \%$ \\
\hline 1973 & 37 & 9.100 .968 & $\mathrm{R} \$ 324.839$ & $\mathrm{R} \$ 3.170 .885$ & $10,24 \%$ \\
\hline 1972 & 38 & 4.395 .308 & $\mathrm{R} \$ 156.881$ & $\mathrm{R} \$ 1.442 .123$ & $10,88 \%$ \\
\hline 1971 & 39 & 2.159 .190 & $\mathrm{R} \$ 77.068$ & $\mathrm{R} \$ 667.064$ & $11,55 \%$ \\
\hline 1970 & 40 & 1.262 .030 & $\mathrm{R} \$ 45.045$ & $\mathrm{R} \$ 367.081$ & $12,27 \%$ \\
\hline 1969 & 41 & 878.814 & $\mathrm{R} \$ 31.367$ & $\mathrm{R} \$ 240.636$ & $13,04 \%$ \\
\hline 1968 & 42 & 1.057 .276 & $\mathrm{R} \$ 37.737$ & $\mathrm{R} \$ 272.514$ & $13,85 \%$ \\
\hline 1967 & 43 & 219.488 & $\mathrm{R} \$ 7.834$ & $\mathrm{R} \$ 53.250$ & $14,71 \%$ \\
\hline 1966 & 44 & 138.142 & $\mathrm{R} \$ 4.931$ & $\mathrm{R} \$ 31.544$ & $15,63 \%$ \\
\hline 1965 & 45 & 64.986 & $\mathrm{R} \$ 2.320$ & $\mathrm{R} \$ 13.966$ & $16,61 \%$ \\
\hline 1964 & 46 & 32.484 & $\mathrm{R} \$ 1.159$ & $\mathrm{R} \$ 6.570$ & $17,65 \%$ \\
\hline 1963 & 47 & 24.357 & $\mathrm{R} \$ 869$ & $\mathrm{R} \$ 4.636$ & $18,75 \%$ \\
\hline 1962 & 48 & 32.468 & $\mathrm{R} \$ 1.159$ & $\mathrm{R} \$ 5.815$ & $19,93 \%$ \\
\hline \multicolumn{2}{|c|}{ TOTAIS } & 7.199 .803 .483 & R\$ 256.981.146 & R\$ 5.952.288.171 & $4,32 \%$ \\
\hline
\end{tabular}

Fonte: Elaboração própria.

representa $73 \%$ da frota.

Considerando a curva de sucateamento proposta por Borba (2008) foi possível chegar às emissões acumuladas dessa frota até o ano de 2050, caso ela continue em circulação, conforme mostrado na Figura 3. Assim calculam-se as emissões evitadas, já que em $205099,9 \%$ da frota vai estar sucateada, independente de um plano de sucateamento acelerado.

Aplicando a curva de sucateamento acima na frota existente é possível chegar às emissões acumuladas para um determinado período. A Tabela 11 mostra as emissões acumuladas por essa frota da data atual até o ano de 2050.
Considerando as emissões fósseis acumuladas para a frota por ano de fabricação e o custo da frota a ser sucateada chegou-se a Tabela 12, que representa o retorno de investimento referente aos créditos de carbono, levando em conta exclusivamente as emissões de $\mathrm{CO}_{2}$ evitadas.

Créditos de carbono ou Redução Certificada de Emissões (RCE) são certificados emitidos quando ocorre a redução de emissão de gases do efeito estufa (GEE). Uma tonelada de dióxido de carbono $\left(\mathrm{CO}_{2}\right)$ ou equivalente corresponde a um crédito de carbono. Este crédito pode ser negociado no mercado internacional (INSTITUTO EDP, 2009)

Pode-se perceber que, sendo o fator de emis- 
são e a quilometragem média percorrida constantes, o sucateamento se torna ainda mais atraente quando considerados os veículos mais antigos, que têm valor mais baixo. Para os veículos fabricados em 1990 o retorno representou $3,92 \%$ do investimento, enquanto para os de fabricação em 1962 o retorno representou $19,93 \%$. Ou seja, quanto mais antigo o veículo, melhor o retorno no investimento caso seja adotado um plano de aceleração da retirada desses veículos pelos governos.

De forma análoga, pode-se determinar o valor a ser pago por veículo que garantirá o retorno de $100 \%$ do investimento realizado. Para tal, estão sendo consideradas as emissões acumuladas por um único veículo até 2050. Considerando a curva de sucateamento de Borba (2008) e as emissões acumuladas até 2050, a frota equivalente a ser considerada para um único veículo é de 7,24. Multiplicando esse valor pelo fator de emissão e pela quilometragem média percorrida, chegou-se a uma emissão evitada de 10.116 quilogramas de $\mathrm{CO}_{2}$ por veículo sucateado, o que equivale a $\mathrm{R} \$ 361,07$ ao preço do índice Reuters de Redução Certificada de Emissões (RCE's) em 07 de setembro de 2009.

\section{CONCLUSÕES}

O Brasil divulgou em 13 de novembro de 2009 seu compromisso de redução de emissões de dióxido de carbono e outros gases causadores de efeito estufa, o qual foi apresentado na Conferência do Clima da Organização das Nações Unidas, em Copenhague, Dinamarca, no mês dezembro. Trata-se de uma redução de $36,81 \%$ a $38,9 \%$ até o ano de 2020 em relação ao que poluiria se nada fosse feito.

$\mathrm{O}$ entendimento é que, para atingir estes quantitativos, todas as alternativas são importantes. Assim, considerando a proposta desse trabalho, com a retirada dos veículos de passeio de fabricação entre 1962 e 1990, as emissões fósseis evitadas de CO2 são de 7,2 milhões de toneladas, ou 7,2 milhões de créditos de carbono. A cotação para o crédito de carbono, pelo índice Reuters de RCE, em 07 de setembro de 2009, foi de $€ 13,52$ (FIESC, 2009). Este quantitativo e esta cotação permite inferir o valor de $€$ 97.341.343,09 para essas emissões evitadas, valor que equivale a
$\mathrm{R} \$ 256.981 .145,76$, considerando a cotação do Euro do dia 08 de setembro de 2009, de R \$2,64 (BANCO DO BRASIL, 2009).

Além desses custos, outros fatores como falta de segurança de veículos antigos, custos com acidentes, seguros, internações, lucros cessantes não foram considerados no cálculo do valor para obter $100 \%$ de retorno financeiro. Há que se considerar ainda as poluições localizada e regional, que acarretam prejuízos à saúde da população.

\section{REFERÊNCIAS}

ÁLVARES JÚNIOR, O. M., LINKE, R. R. A. Metodologia simplificada de cálculo das emissões de gases do efeito estufa de frotas de veículos no Brasil. 2002. Disponível em: <http://homologa.ambiente.sp.gov.br/ proclima/PDF/ inventario_efeitoestufa.pdf $>$. Acesso em: 07 set. 2009.

ALVIM, C. F., FERREIRA, O. C., VARGAS, J. I. Revisitando a concentração do metano na atmosfera. Economia e Energia, n. 65, p. 29-35, 2008.

ANFAVEA - ASSOCIAÇÃO NACIONAL DOS FABRICANTES DE VEÍCULOS AUTOMOTORES. Anuário 2008. Disponível em: <http://www.anfavea. com.br/ anuario2008/indice.pdf $>$. Acesso em: 02 jun. 2009.

BANCO DO BRASIL. Euro. Disponível em: $<$ http:// cotacoes.agronegocios-e.com.br/investimentos /conteudoi.asp? option $=$ dolar \& title $=\% 20$ Euro $>$. Acesso em: 08 set. 2009.

BORBA, B. S. M. C. Metodologia de regionalização do mercado de combustíveis automotivos no Brasil. 2008. 136p. Dissertação (Mestrado em Ciências em Planejamento Energético) - Programa de Pós-Graduação em Engenharia, UFRJ, Rio de Janeiro, 2008.

CNT - CONFEDERAÇÃO NACIONAL DO TRANSPORTE. Boletim Ambiental: Emissões de $\mathrm{CO}_{2}$. 2007. Disponível em: <http://www.cnt.org.br/ arquivos/downloads/despoluir/BOLETIM DESPOLUIR.pdf >. Acesso em: 20 mai. 2009. 
COMPANHIAAMBIENTAL DO ESTADO DE SÃO PAULO-CETESB. Proconve: continuação. Disponível em: <http://www.cetesb.sp.gov.br/Ar/emissoes / proconve2.asp>. Acesso em: 09 set. 2009.

EMPRESA DE PESQUISA ENERGÉTICA. Balanço Energético Nacional 2009: ano base 2008: Resultados Preliminares. Rio de Janeiro: EPE, 2009.

EURONEWS. Berlim aumenta bônus à troca de carros. 08 abr. 2009. Disponível em: $<$ http://pt.euronews. net/2009/04/08/berlim-aumenta-bonus-a-troca-decarros>. Acesso em: 30 mai. 2009.

FIESC - SISTEMA FEDERAÇÃO DAS INDÚSTRIAS DE SANTA CATARINA. Cotação $\mathrm{CO}_{2}$. Disponível em: <http://www2.fiescnet.com.br/web/ pt/ site topo/mdl/info/cota-ao-co2 $>$. Acesso em: 08 set. 2009.

FIPE - FUNDAÇÃO INSTITUTO DE PESQUISAS ECONÔMICAS. Tabela FIPE. Disponível em: $<$ http://www.fipe.org.br/web/index.asp > . Acesso em: 21 ago. 2009.

INSTITUTO EDP. Crédito de carbono. Disponível em: <http://www.institutoedp.com.br/institutoedp/ credito_carbono/credito_carbono.asp $>$. Acesso em: 07 set. 2009.

IPCC - INTERGOVERNMENTAL PANEL ON CLIMATE CHANGE. Climate Change 2007: The Physical Science Basis. Contribution of Working Group I to the Fourth Assessment Report of the Intergovernmental Panel on Climate Change. United Kingdom and New York: Cambridge University Press, 2007.

MANECHINI, G., CAMAROTTO, M. Inspeção vai exigir reciclagem de veículos no Brasil. 2008. Disponível em: <http://www.aea.org.br/aea2009/comunic/ noticias aea/inspecao.php>. Acesso em: 25 mai. 2009.

MEIRA, R. Poluição atmosférica: efeito estufa. 2002. Disponível em: $<$ http://www.rudzerhost.com/ambiente/estufa.htm>. Acesso em: 30 abr. 2009.
MENDES, F. E. Avaliação de programas de controle de poluição atmosférica por veículos leves no Brasil. 2004. 179f. Tese (Doutorado em Ciências em Planejamento Energético) - Programa de Pós-Graduação em Engenharia, UFRJ, Rio de Janeiro, 2004.

MEYER, C. R. Implicações energético-ambientais de esquemas de sucateamento de automóveis no Brasil. 2001. 108p. Dissertação (Mestrado em Ciências em Planejamento Energético) - Programa de Pós-Graduação em Engenharia, UFRJ, Rio de Janeiro, 2001.

QUATRO RODAS. Autoserviço: mais vendidos. Disponivel em: < http://quatrorodas.abril.com.br/ QR2/autoservico/top50/2008.shtml>. Acesso em: 12 ago. 2009.

SILVA, C. Renovação de frota de carros é lenta. 2008. Disponivel em: <http://www.comven.com. br/pub/index.php/comunicacao-de-venda/Noticias/ Renovacao-de-frota-de-carros-e-lenta.html>. Acesso em: 12 jun. 2009.

SINDIPEÇAS - SINDICATO NACIONAL DA INDÚSTRIA DE COMPONENTES PARA VEÍCULOS AUTOMOTORES. Desempenho do Setor de Autopeças 2009. São Paulo: SINDIPEÇAS, 2009.

. Estudo da frota circulante brasileira. São Paulo: SINDIPEÇAS, 2008.

SOARES, L. H. de B. et al. O etanol brasileiro e a mitigação na emissão dos gases de efeito estufa. Revista Brasileira de Bioenergia. Rio de Janeiro, ano 3, n. 6, p. 42-47, mai. 2009.

SZWARCFITER, L. Opções para o aprimoramento do controle de emissões veiculares de poluentes atmosféricos no Brasil: uma avaliação do potencial de programas de inspeção e manutenção e de renovação acelerada da frota. 2004. 261p. Tese (Doutorado em Ciências em Planejamento Energético) - Programa de Pós-Graduação em Engenharia, UFRJ, Rio de Janeiro, 2004.

WILLS, W. O aumento da eficiência energética 